\title{
Preparation of Charcoal Flowers
}

Yoichiro Nakanishi, Kanenaga Fujii and Yoshihiro Sawada

(Received March 27, 1991)

\author{
Government Industrial Research Institute of Osaka \\ 1-8-31, Midorigaoka, Ikeda, Osaka, 563 Japan
}

\begin{abstract}
Charcoal flowers had been used at tea ceremony in Edo era in Japan by the name of "Ohanazumi", but they remained in the literature only its name without any description on their preparation method. In the present study a preparation of charcoal flowers was tried by the application of pre-oxidation process. Flowers were dried at first and then oxidized in a furnace or in an air oven at temperatures between $200^{\circ} \mathrm{C}$ and $300^{\circ} \mathrm{C}$. The flowers thus oxidized were put in to a quartz vessel and carbonized by heating in a crucible furnace from $250^{\circ} \mathrm{C}$ to $600^{\circ} \mathrm{C}$ in a flow of argon gas with a heating rate of $120^{\circ} \mathrm{C} / \mathrm{hr}$. The charcoal flowers could easily be prepared by this method in a short time of four hours or so. The charcoal flowers obtained in the present study were those from chrysanthemum, babies-breath, sazanka, fuyou (a kind of rose mallow) and etc. Art charcoals from leaves of Japanese holly and ginkgo, mandarin oranges and dried mushrooms (Shiitake) were also made.
\end{abstract}

KEYWORDS: Charcoal flower, Pre-oxidation process, Carbonization process, Art charcoal

\section{Introduction}

High classes in the Edo era in Japan, such as Daimyou, enjoyed black flowers at the tea ceremony. These black flowers were made from raw flowers by carbonization and were called "Ohanazumi" in Japanese. Since the process to make the Ohanazumi had been kept secret by the power, the details of the process were lost after the collapse of the Edo Shogunate. Therefore, the name of Ohanazumi has remained only on the literature ${ }^{1)}$.

In 1986 Harada recalled the method to make charcoal flowers about 100 years after from the lost ${ }^{2), 3)}$. But Harada didn't report any preparation process of the charcoal flowers. After that Hishiyama and Yoshida reported successfully a method to prepare charcoal flowers of rose by their research group and structural study of the charcoal flowers mainly made by scanning electron microscopy 4 ). They prepared dry flowers of rose at first and then immediately carbonized them up to $600^{\circ} \mathrm{C}$ with 10 hours in non-oxidative atmosphere ${ }^{5)}$. In the present study we succeeded to make charcoal flowers in a short time by applying pre-oxidation process invented by Shindo et al. for preparation of PAN based carbon fiber ${ }^{6}$.

\section{Preparation process}

The pre-oxidation process is the one used in preparation of PAN-based and pitch-based carbon fibers, but not cellulose-based carbon fiber ${ }^{7)}$. The pre-oxidation process used in this study was first an application on carbonization of materials of which main component is cel- 


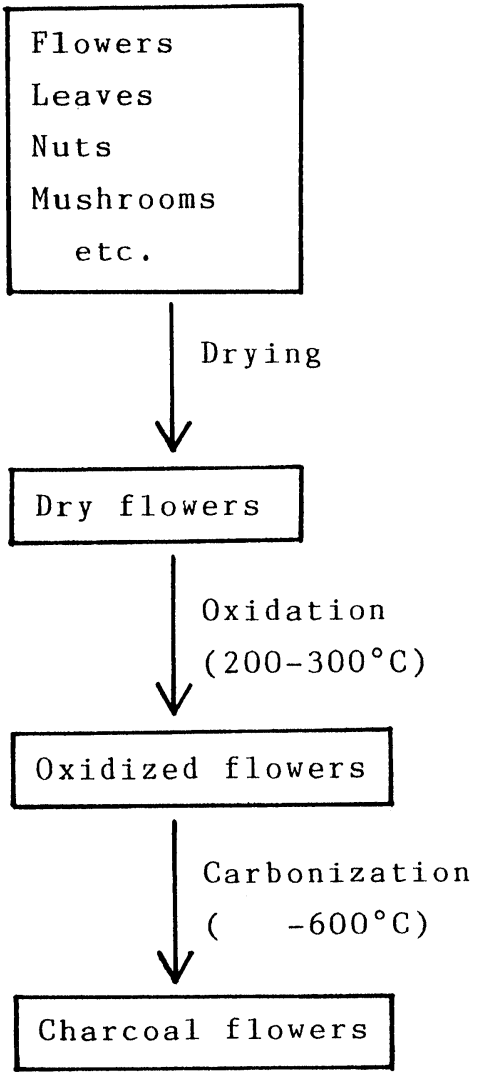

Fig. 1 Preparation process of charcoal flowers.

lulose.

Twigs with flowers and leaves, or flowers and leaves themselves were dried in a ventilated room and/or in a decicator filled by silicagel. In this process the floweres changed to dry flowers. They were then oxidized in a furnace by heating from $200^{\circ} \mathrm{C}$ to $300^{\circ} \mathrm{C}$ with a heating rate of $120^{\circ} \mathrm{C} / \mathrm{hr}$, and/or oxidized in an air oven at $250^{\circ} \mathrm{C}$ for about three hours, as shown in Fig. 1. They were further put into a quartz vessel (Fig. 2) and the vessel was heated in the crucible furnace in a flow of $\mathrm{Ar}$ gas from $250^{\circ} \mathrm{C}$ up to $600^{\circ} \mathrm{C}$ with a heating rate of $120^{\circ} \mathrm{C} / \mathrm{hr}$. The final products obtained were charcoals of flowers, twigs, leaves and others.

Weights and lengths of petals and leaves before and after oxidation and carbonization were measured. In this study charcoal flowers were obtained from many kinds of flowers, for

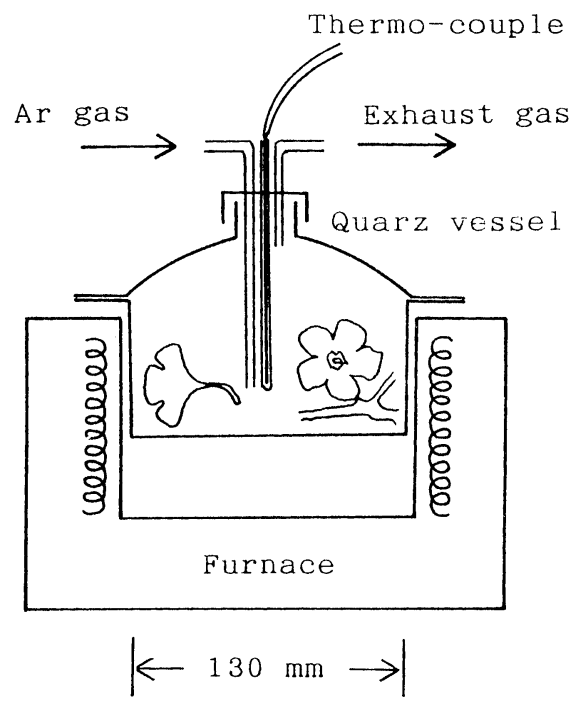

Fig. 2 Apparatus for carbonization.

examples crysanthemum, babies-breath, sazanka, fuyou (a kind of rose mallow), rose of sharon, and etc. Art charcoals from leaves of Japanese holly and ginkgo, mandarin oranges and dried mushrooms (shiitake) etc. were also made by the same method.

\section{Results and Discussion}

\subsection{Changes in weights and dimensions}

Weights and lengths were measured to know yields and changes in shape during processes and to know those differences among flowers. Representatives of weight changes in preparation processes are plotted in Fig. 3. Since in each raw flower, petals and leaves have different water content, the weight losses of petals by drying varried between 60 and $90 \%$ (Fig. 3 (a)), while those of leaves between 17 and 57\% (Fig. 3 (b)). For the case of rose weight loss of a petal was $83 \%$, but that of a leaf only $56 \%$. Weight losses by oxidation were between 49 and $54 \%$ for petals, and between 40 and $45 \%$ for leaves. Final yield from raw materials to charcoal flowers were between 2 and 14\% for petals, and between 11 and $30 \%$ for leaves. These yields are quite reasonable, because yield of carbonaceous materials from cellulose by slow heating in carbonization process is about 


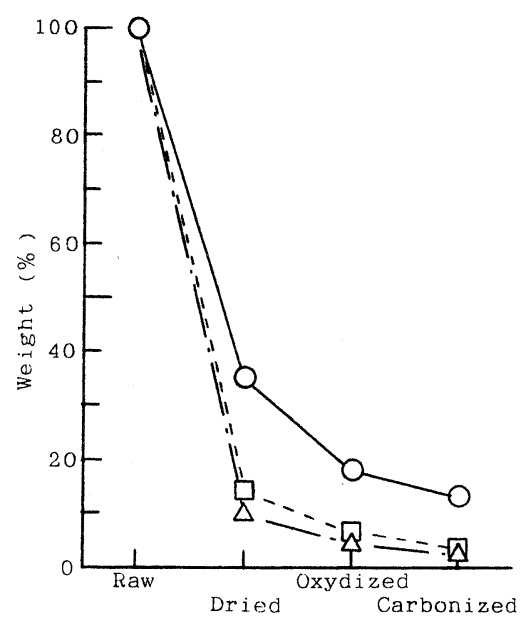

Fig. 3 (a) Weight changes of petals during preparation process of charcoal flowers.

$$
\begin{aligned}
\longrightarrow-\triangle-\square & : \text { chrysanthemum, } \\
--\square-- & \text { : fuyou (a kind of rose mal- } \\
& \text { low). }
\end{aligned}
$$

$10 \% 1), 7)$.

One of the component of dried shiitake (mashroom) is $20 \%$ of protein, so we doubted if we could obtain charcoals from shiitake. But carbonaceous shiitake was obtained and the weight yield of carbonization from raw shiitake was $2.4 \%$, as shown in Fig. 3 (b). The carbonization yield was similar to those of rose and huyou petals of which main component is cellulose.

Effects of the pre-oxidation can be summarized as follows; (1) to shorten carbonization time, (2) to increase yield, and (3) to strengthen charcoal flowers. These effects seem to be caused by oxidation bridging (cross linking) inter or intra cellulose molecules. The oxidation bridging prevents rapid decomposition of the cellulose molecule and lowering of the molecular weight.

The dimension (length) changes of the charcoal flowers in the processes are plotted in Fig. 4. The shrinkage of a petal of rose by drying was $45 \%$ and larger than those of the chrysanthemum $(18 \%)$ and fuyou $(15 \%)$ as

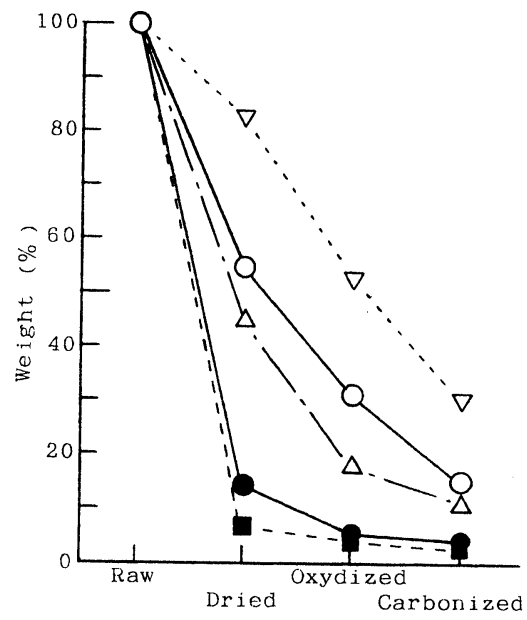

Fig. 3 (b) Weight changes of leaves and others during preparation process of charcoal floweres and art charcoals. - - $\nabla-.$. : leaf of sazanka, $--\Delta-\cdots$ : ginkgo leaf, - - - - : shiitake, and —_ : mandarin orange.

shown in Fig. 4 (a). The shrinkage of leaves by drying were $0 \sim 17 \%$ (Fig. 4 (b)) and smaller than those of petals. The shrinkages of dry leaves by oxidation were comparatively smaller than those of dry petals. Length retention after carbonization from raw material was $40 \sim 60 \%$ for petals and $60 \sim 90 \%$ for leaves.

The shrinkage of cap diameter of dried shiitake by oxidization was $45 \%$ to the raw one and it was larger than those of leaves (Fig. 4 (b)). The length retention of cap of shiitake after carbonization was $42 \%$ relative to the raw material, being close to that of the rose petal. However, the shrinkage of shiitake from the raw one seems to be larger than those of rose or other flowers, because the cap surface area of charcoal shiitake was only $17 \%$ of the raw.

\subsection{Feature of charcoal flowers}

Charcoal flowers obtained were beatiful and very mysterious. Photographs of charcoal flowers are shown in Fig. 5. Petals of rose (Fig. 5 (a)) and sazanka (Fig. 5 (b)) wrinkled after drying, and the wrinkles remained in the charcoal 


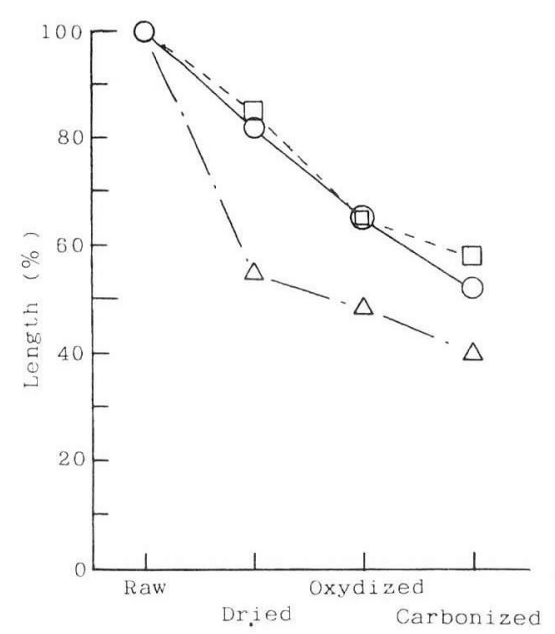

Fig. 4 (a) Dimension changes of petals during preparation process of charcoal flowers.

- $\quad$ : chrysanthemum,

$-\Delta--$ : rose, and

$--\square--$ : fuyou.

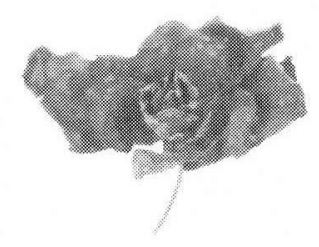

(a)

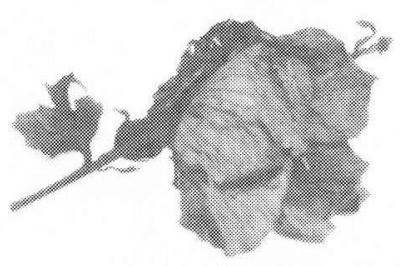

(c)

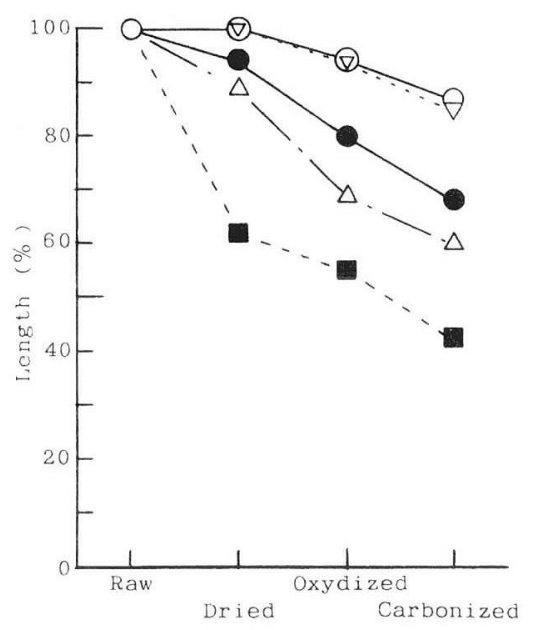

Fig. 4 (b) Dimension changes of leaves and others during paration process of charcoal floweres and art charcoals.

-.. $\nabla--$ : leaf of sazanka,

$--\triangle-\cdots$ : ginkgo leaf,

-

- - - : cap of shiitake, and

—_ : mandarin orange.

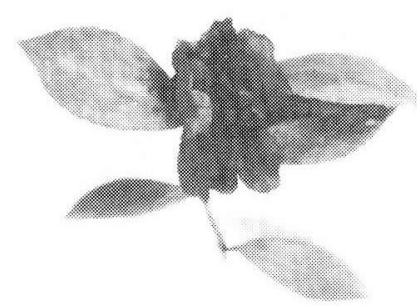

(b)

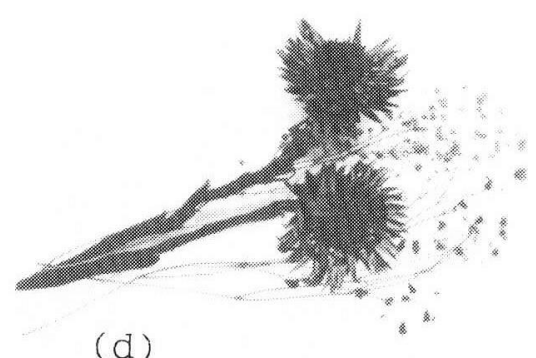

(d)

Fig. 5 Charcoal flowers.
(a) rose,
(b) sazanka,
(c) fuyou, and
(d) babies-breath and ammobium alatum. 
flowers with twist distortions. For the case of rose, pockmarks remained on petals of the charcoal flowers, as shown in Fig. 5 (a), because larger granular silicagel was used for drying. Petals of fuyou were distorted in all process (Fig. 5 (c)), because they were large and thin. Most of charcoal flowers obtained were brittle and fragile, because they were too thin, and carbonization temperature might be low.

A mandarin orange used was much crumpled after drying, but its charcoal became a sphere of good shape, because of its dense shell and shell expansion by steam generation at oxidation process.

\subsection{Improvement to be established in future}

There are many factors to be improved in future for the charcoal flowers to make them complete forms and to apply them in many fields such as room ornament and trimmings. They are (1) shrinkage and distortion of the charcoal flowers from the raw, especially for the case of trimmings, (2) strength of the charcoal flowers, and (3) preparation time. If the charcoal flowers keep their original shape nicely, have sufficient strength to handle and can be made in a short time, it will be attractive and excellent marketable-goods by treating with plastics, etc.

\section{Summary}

Charcoal flowers and art charcoals could easily be obtained from many dry flowers, and also from dried leaves, fruits and mushrooms by oxidizing prior to carbonization. The time required to prepare carbonized products from the oxidized in this study was four hours or so. They could be marketable goods if the improvements on retention of original shapes, on strengths and on preparation times are established.

\section{References}

1) S. Kishimoto, "Mokutan no hakubutushi", Sougo kagaku shuppan (1988)

2) R. Harada, Flowerist, 1986 [No. 5] 5

3) R. Harada, Nippon Keizaishinbun, p. 32, dated July 10, 1986

4) Y. Hishiyama and A. Yoshida, Gakushinshiryou 117-192B-1 (1986)

5) E. Sotoya, M. Koyama and Y. Hishiyama, Japanese Patent pending, Tokkai-sho 63176199 (1988)

6) A. Shindo, R. Fujii and T. Sengoku, Japanese patent, No. 304892.

7) M. Tang and R. Bacon, Carbon 2, 211 (1964) 